\title{
Improved Vehicle-for-Grid (iV4G) Mode: Novel Operation Mode for EVs Battery Chargers in Smart Grids
}

\author{
Vitor Monteiro, J. G. Pinto, João L. Afonso
}

\begin{abstract}
The experimental validation of a novel operation mode for electric vehicles (EVs) to support the grid power quality is presented. The proposed operation mode, denominated improved vehicle-for-grid (iV4G), is directly associated with the EVs operation aiming the compensation of power quality problems associated with current harmonic distortion and reactive power, improving the total power factor of the electrical installation. Simultaneously with the proposed iV4G, where the $\mathrm{EV}$ injects current harmonics and provides reactive power, the EV can exchange active power with the grid (grid-to-vehicle, G2V, to charge the batteries or vehicle-to-grid, V2G, to deliver energy back to the power grid). In this paper, the proposed iV4G operation mode is experimentally validated with a developed EV battery charger prototype connected to an electrical installation of $230 \mathrm{~V}, 16 \mathrm{~A}, 50 \mathrm{~Hz}$. The control strategies of the iV4G operation mode and the used prototype are described in detail along the paper. The achieved results confirm the feasibility and good performance of the proposed iV4G operation mode, working alone, and also when associated with the G2V and V2G operating modes.
\end{abstract}

Index Terms-Electric Vehicle, Improved Vehicle-for-Grid (iV4G), Power Quality, Smart Grids.

\section{INTRODUCTION}

$\mathrm{T}$ HE proliferation of electric vehicles (EVs) represents a huge contribution for the power grids in terms of control strategies and future trends [1][2][3]. In this context, new challenges and opportunities are emerging in terms of industrial electronics [4], mainly for the EV collaboration with the uncertainty energy production from renewables [5], and with the energy management and optimized operation of smart homes and microgrids [6][7][8]. Distinct operating strategies, including the power ratings, for the EV operation in a microgrid and considering the introduction of renewables is presented in [9]. The EV introduction into the power grid through the grid-to-vehicle $(\mathrm{G} 2 \mathrm{~V})$ mode and the interaction with renewable energy sources towards to reduce costs and emissions is proposed in [10]. The EV introduction through the vehicle-to-grid ( $\mathrm{V} 2 \mathrm{G})$ mode, i.e., delivering energy from the
EV back to the power grid, and also considering renewable energy sources, is presented in [11]. The EV operation through the $\mathrm{G} 2 \mathrm{~V}$ and $\mathrm{V} 2 \mathrm{G}$ operation modes including the distribution grid constraints in order to minimize the total operating costs and the regulation of the power grid voltage frequency is presented in [12] and in [13]. A review about the impact of the G2V and V2G modes on distribution systems is addressed in [14], and a dynamic active power control of EVs battery chargers during both G2V and V2G modes and according to the operation of the other electrical appliances is proposed in [15]. Besides the relevance of the $\mathrm{G} 2 \mathrm{~V}$ and $\mathrm{V} 2 \mathrm{G}$ modes, the vehicle-to-home, vehicle-to-vehicle, and home-to-vehicle, are being discussed as new paradigms for the compelling operation of EVs in smart grids [16][17][18]. It is relevant to note that these operation modes are controlled only for exchanging active power in bidirectional mode between the EV and the power grid.

Besides exchange active power with the grid, the EV charger can also be designed and controlled to compensate power quality problems, mainly, the current harmonics and the power factor of the electrical installation where it is plugged-in. This new challenge is more relevant knowing that it is not necessary to use any energy from the EV battery, and that the derivative costs from power quality problems are considerable high around the world [19][20][21]. Thus, the EV can be controlled as a distributed and dynamic active power filter throughout the power grid, representing an added value to support grid power quality. Analogous challenges are presented through computer simulations in [22] and [23], but for the EV powertrain. The possibility of the EV operation just producing reactive power to the power grid is presented in [24], [25], [26], [27], and in [28], but without the capability to compensate current harmonics, which is an important new contribution of this paper. The possibility of using an EV charger for harmonics and reactive power compensation only during the charging process $(\mathrm{G} 2 \mathrm{~V})$ is presented in [29], but an experimental validation also during V2G operation is not presented, which is a relevant disadvantage, since the main EV manufactures are introducing the $\mathrm{V} 2 \mathrm{G}$ mode as possibility. Moreover, the possibility of 


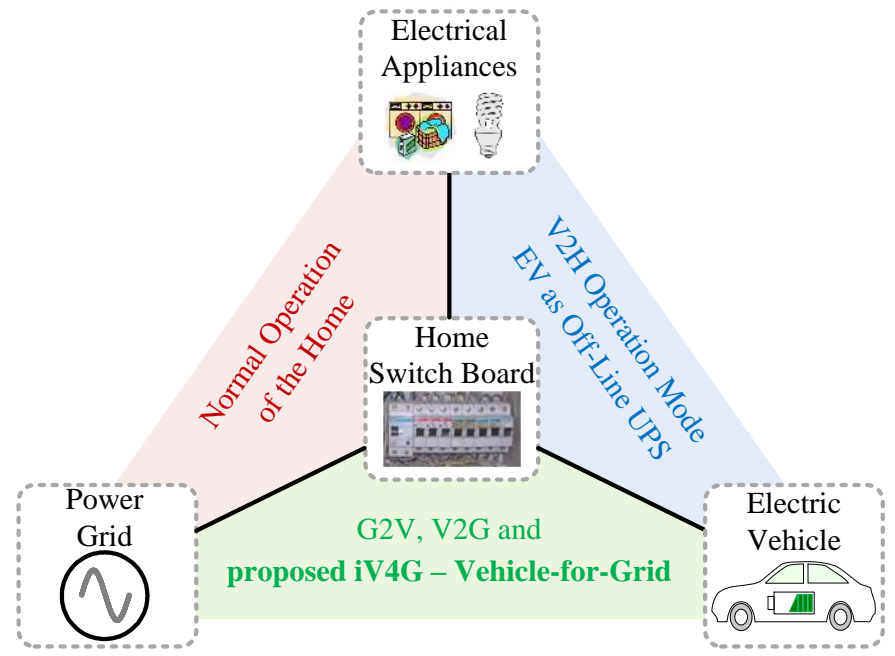

Fig. 1. Proposed iV4G operation mode for an electric vehicle into a home.

compensating harmonics and reactive power independently of operating in G2V or V2G mode is also not presented. The challenge of using an EV charger operating in four quadrants is presented in [30], where an experimental validation during both $\mathrm{G} 2 \mathrm{~V}$ and $\mathrm{V} 2 \mathrm{G}$ modes is presented, and considering reactive power compensation, but not current harmonics compensation. Similar features as the proposed in this paper are presented in [31], but an external EV supply equipment (EVSE) is required, because the necessary coupling passive filters are inside the EVSE, limiting the possibility of connecting the EV to any power outlet. which represents a relevant drawback. Moreover, the claimed features are only validated by simulation results. The opportunity for current harmonics and reactive power compensation is presented in [32], but for an off-board three-phase charging station (i.e., an active power filter that can be used as EV charger). Another off-board three-phase charger is proposed in [33], where the obtained results show only current harmonics compensation, without reactive power compensation or the combined operation with the $\mathrm{G} 2 \mathrm{~V}$ and V2G modes.

This paper presents a detailed experimental validation of a proposed bidirectional single-phase on-board EV battery charger, with new integrated functionalities, denominated improved vehicle-for-grid (iV4G) mode. The main contribution of this paper consists in adding a new function to EV battery chargers without increasing their cost or volume. This new functionality is not available or predicted yet for EVs, and will contribute with clear benefits to the EV introduction into the power grid, representing an asset for the smart grids operation. From the power grid point of view, the proposed operation mode will be more relevant since the reactive power and current harmonics compensation can be managed according to the power grid requirements. Fig. 1 illustrates the integration of the EV charger into a home through the proposed operation mode, which can be used during the G2V mode, during the V2G mode, or when the EV is just plugged-in, and not operating in the G2V or V2G modes (in this case, it is only used the ac-dc converter of the charger). It is important to note that, all of these new features are available in a single on-board EV charger, representing a benefit in counterpart to the classical structures presented in the state-of-the-art.

The rest of this paper is organized as follows. Section II presents the system description, while section III presents the proposed control algorithms for the EV charger during the $\mathrm{G} 2 \mathrm{~V}, \mathrm{~V} 2 \mathrm{G}$ and iV4G modes. The developed EV charger prototype and the experimental validation of the $\mathrm{G} 2 \mathrm{~V}, \mathrm{~V} 2 \mathrm{G}$ and iV4G operation modes are presented in section IV. Finally, section $\mathrm{V}$ presents the conclusions.

\section{ANALYSIS AND SYSTEM DESCRIPTION}

Detailed simulation results about the principle of operation, focusing on the proposed iV4G mode and the architecture of the EV charger, are presented in this section.

\section{A. Principle of Operation}

Fig. 2 presents the principle of operation and the typical voltage and current waveforms in the ac side of an EV charger, operating in three distinct modes: traditional G2V; proposed iV4G combined with the $\mathrm{G} 2 \mathrm{~V}$; and proposed iV4G. In this figure, $v_{g}$ denotes the power grid voltage, and $i_{h}, i_{e a}$, and $i_{e v}$ indicates, respectively, the home current, the electrical appliances current and the EV charger current (composed by the sum of two components: current used to charge the batteries $i_{\text {ev_c }}$ and current used to compensate the harmonic distortion $i_{e v_{-} \mathrm{f}}$ ). These results were obtained with the simulation tool PSIM v9.0 and with a time-step of $1 \mu \mathrm{s}$. In the simulation model were considered all the details of the developed EV charger prototype (cf. section IV). Moreover, to simulate realistic conditions of operation, a power grid voltage with harmonic distortion was considered.

During the first time interval (from $0.1 \mathrm{~s}$ to $0.16 \mathrm{~s}$ ), the EV charger is not plugged-in at home, therefore, the home current $\left(i_{h}\right)$ corresponds to the electrical appliances current $\left(i_{e a}\right)$. The electrical appliances current presents a total harmonic distortion (THD) of $18.9 \%$ and a total power factor (TPF) of 0.71 . The power grid voltage $\left(v_{g}\right)$ also presents a THD of $2.1 \%$ in order to simulate a realistic operating condition. During the second time interval (from $0.16 \mathrm{~s}$ to $0.26 \mathrm{~s}$ ), the EV charger performs the battery charging process ( $\mathrm{G} 2 \mathrm{~V}$ operation mode). In this period, the EV current $\left(i_{e v}\right)$ is always sinusoidal and increases slowly. In this case, the EV current is composed only by the component used to charge the batteries $\left(i_{e_{\nu} \_}\right)$. The measured THD in steady state of the EV current $\left(i_{e v}\right)$ was $2.3 \%$ and the TPF was 0.99 . On the other hand, for the home current $\left(i_{h}\right)$, the measured THD was $10.1 \%$ and the TPF was 0.93 . During the third time interval (from $0.26 \mathrm{~s}$ to $0.36 \mathrm{~s}$ ), the EV charger is controlled to operate as iV4G (compensating the current harmonic distortion and the reactive power) and also to perform the battery charging process ( $\mathrm{G} 2 \mathrm{~V}$ operation mode). During this time interval, the home current $\left(i_{h}\right)$ corresponds to the sum of the electrical appliances current $\left(i_{e a}\right)$ with the EV current $\left(i_{e v}\right)$. As result of the iV4G mode, the home current became sinusoidal with a THD of $1.3 \%$ and a TPF of 0.99 , highlighting an important contribution of the subject of this paper. The EV current $\left(i_{e v}\right)$ is distorted (sum of the current to charge the batteries with the current to compensate the electrical appliances harmonics), with a measured THD of $14.9 \%$ and a TPF of 0.83 . In this case, 


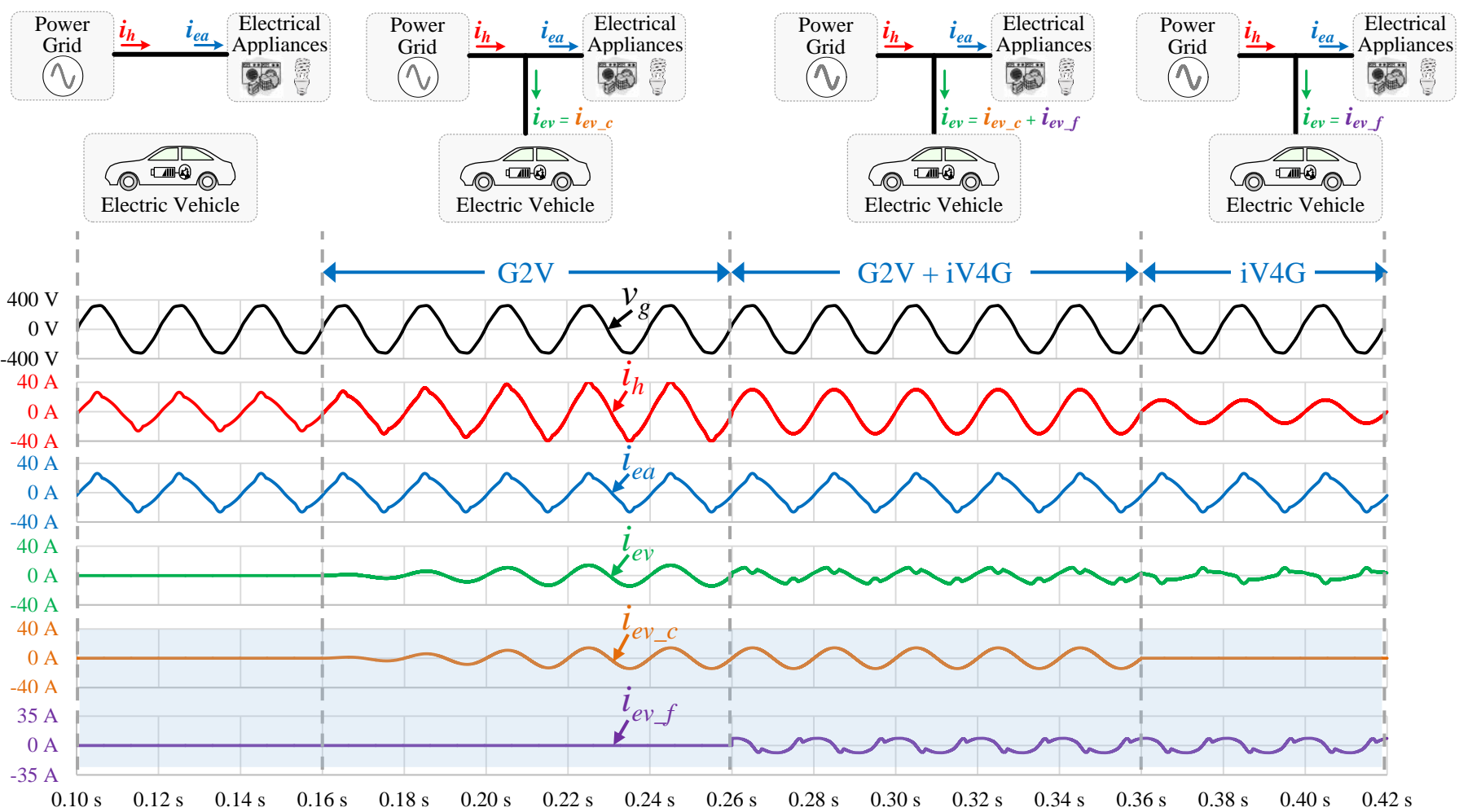

Fig. 2. Principle of operation of the G2V and iV4G modes: Power grid voltage $\left(v_{g}\right)$; Home current $\left(i_{h}\right)$; Electrical appliances current $\left(i_{e a}\right)$; EV current $\left(i_{e v}\right)$; Component of $i_{e v}$ used to charge the batteries $\left(i_{e v_{-}}\right)$; Component of $i_{e v}$ used to compensate the harmonic distortion $\left(i_{e v_{-} f}\right)$ of the electrical appliances current.

the EV current is composed by the component used to charge the batteries $\left(i_{e v_{-} c}\right)$ and by the component used to compensate the harmonic distortion $\left(i_{e v_{-} \mathrm{f}}\right)$ of the electrical appliances current. Due to the current harmonics compensation, the rms value of the home current was reduced from $25.7 \mathrm{~A}$ to $21.2 \mathrm{~A}$ (with a sinusoidal waveform), allowing mitigate the energy transmission losses and optimize the transformers usage. During the fourth time interval (from $0.36 \mathrm{~s}$ to $0.42 \mathrm{~s}$ ) the battery charging process is completed, but the EV charger continues to compensate the harmonic distortion, i.e., it operates with the iV4G mode. The home current $\left(i_{h}\right)$ is also sinusoidal with a THD of $2.1 \%$ and a TPF of 0.99 . The EV current $\left(i_{e v}\right)$ is distorted to compensate the current harmonics of the electrical appliances, where the measured THD was $38.4 \%$ and the TPF was 0.8. In this case, the EV current is composed only by the component used to compensate the harmonic distortion $\left(i_{e v_{-}}\right)$of the electrical appliances current. This new operation mode is more relevant taking into consideration that is not required any energy from the EV batteries, and the EV can contribute to support the grid power quality, providing current harmonics compensation and reactive power. Moreover, this operation mode is very different of the G2V and V2G modes, where is only exchanged active power between the $\mathrm{EV}$ and the power grid.

\section{B. EV Charger Architecture}

The proposed mode (iV4G) was evaluated with a bidirectional EV charger prototype, which is composed by an ac-dc converter and a dc-dc converter. The ac-dc is a three-level $\left(+v_{d c}, 0,-v_{d c}\right)$ full-bridge converter and is used to control the ac current and the dc-link voltage. The dc-dc is a half-bridge converter and is used to control the batteries charging voltage and current, or the discharging current. The overall system model, shown in Fig. 3, is composed of the power grid, the power converters of the EV charger, and the EV batteries. The EV battery charger specifications are presented in Table I. According to the selected required mode, the ac-dc can operate as an active rectifier (the energy follows from the power grid to the batteries) or as a grid-tie inverter (the energy follows from the batteries to the power grid). The dc-dc can operate as a buck converter (charging the batteries with constant current or constant voltage, $\mathrm{G} 2 \mathrm{~V}$ ) or as a boost converter (discharging the batteries with constant current, V2G).

\section{PROPOSED CONTROL AlgORITHMS}

A detailed analysis of the proposed control algorithms for performing the $\mathrm{G} 2 \mathrm{~V}, \mathrm{~V} 2 \mathrm{G}$ and $\mathrm{iV} 4 \mathrm{G}$ operation modes is presented in this section. Aiming to synchronize the grid current reference with the power grid voltage a phase-locked loop (PLL) algorithm is used [34], where two signals ( $v_{\text {plls }}$ and $v_{\text {pllc }}$ ) corresponding, respectively, to the direct and quadrature components of the power grid voltage are obtained. The flowchart of the proposed control system is shown in Fig. 4 and is described in detail as following. In a first step, the operation mode $(\mathrm{G} 2 \mathrm{~V}, \mathrm{~V} 2 \mathrm{G}$ or $\mathrm{iV} 4 \mathrm{G})$ is selected. If the $\mathrm{G} 2 \mathrm{~V}$ is selected, then the charging stage constant current (CC) or the constant voltage (CV) is selected. After that, is selected the combined operation with the iV4G or the simple operation to charge the batteries $(\mathrm{G} 2 \mathrm{~V})$, where the equations 3,4 and 5 are used to establish the EV current reference $\left(i_{e v}{ }^{*}\right)$. If the V2G is selected, 


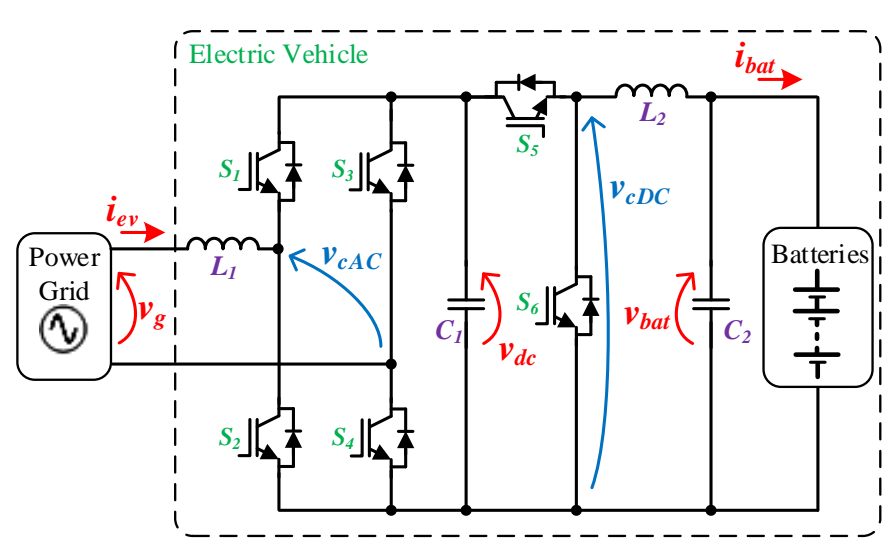

Fig. 3. Architecture of the EV battery charger.

TABLE I

SPECIFICATIONS OF THE EV CHARGER

\begin{tabular}{lll}
\hline \hline Parameter & Value & Unit \\
\hline Nominal Grid Voltage & $230 \pm 10 \%$ & $\mathrm{~V}$ \\
Frequency & $50 \pm 1 \%$ & $\mathrm{~Hz}$ \\
Sampling Frequency & 40 & $\mathrm{kHz}$ \\
Maximum Input Current & 16 & $\mathrm{~A}$ \\
Maximum Input Current Ripple & 0.5 & $\mathrm{~A}$ \\
Maximum Input Power & 3.6 & $\mathrm{kVA}$ \\
THDi @ Full Load & $<2.5 \%$ & - \\
TPF @ Full Load & $>0.99$ & - \\
Output Voltage Range & 250 to 400 & $\mathrm{~V}$ \\
Maximum Output Dc Current & 10 & $\mathrm{~A}$ \\
Switching Frequency & 20 & $\mathrm{kHz}$ \\
Power Density & 0.43 & $\mathrm{~kW} / \mathrm{L}$ \\
\hline \hline
\end{tabular}

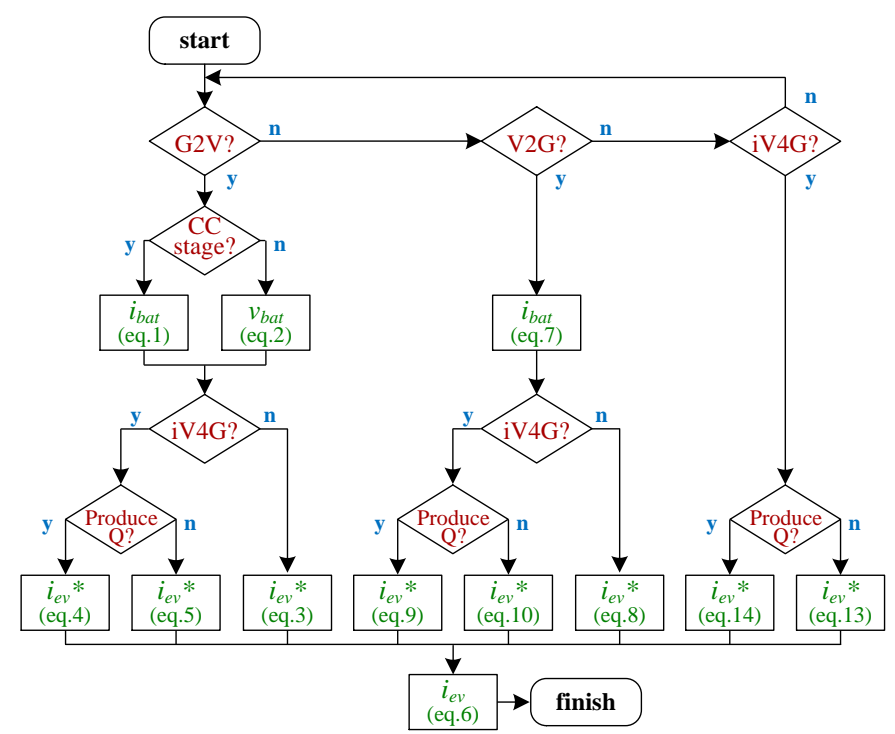

Fig. 4. Flowchart of the proposed control system.

then the constant current discharging mode is selected.

After that, is selected the combined operation with the $\mathrm{iV} 4 \mathrm{G}$ or the simple operation to discharge the batteries (V2G), where the equations 10,11 and 12 are used to establish the EV current

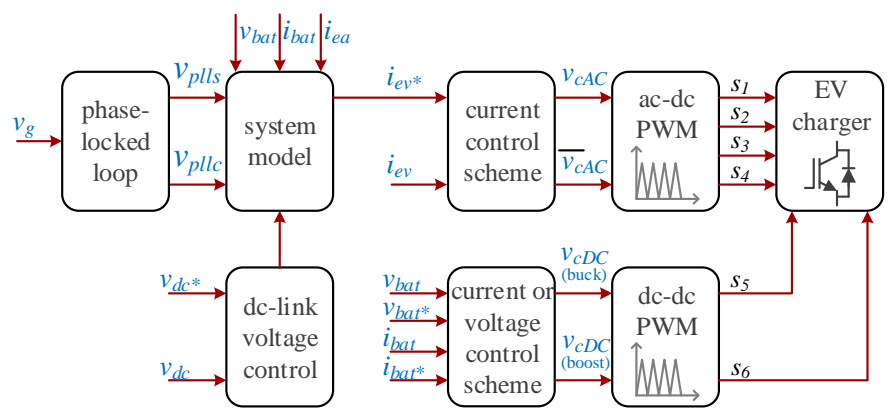

Fig. 5. Block diagram showing the structure of the system control scheme.

reference $\left(i_{e v} *\right.$. Finally, if the $\mathrm{iV} 4 \mathrm{G}$ is selected, then the operation to compensate the harmonic distortion of the electrical appliances (equation 13) or the operation to produce reactive power (equation 14) is selected. A block diagram showing the structure of the system control is presented in Fig. 5. Both converters are controlled individually and based on a closed-loop control scheme. During a control cycle, the PLL is the first implemented function, and based on the model of the converters, the dc variables, and the dc-link voltage control, is established the reference for the EV current. After that, are implemented the functions to control the variables of both converters, and are generated the IGBTs control signals using PWM. A more detailed description is presented in the next sections.

\section{A. Charging the EV Batteries}

The charging process is the main purpose of the EV charger. According to the battery technology, the dc-dc converter requires two control strategies: constant current (CC) and constant voltage (CV) [35]. Analyzing Fig. 3, the voltage established by the converter $\left(v_{c D C}\right)$ in order to maintain a charging process with constant current (CC) is obtained from:

$v_{c D C}(\mathrm{t})=v_{\text {bat }}(t)+v_{L 2}(t)$,

which can be rewritten as:

$v_{c D C}(\mathrm{t})=v_{b a t}(t)+L_{2} \frac{d i_{L 2}(t)}{d t}$.

The discrete implementation of the control strategy, obtained considering the application of the backward Euler method as:

$\frac{d i_{L 2}(t)}{d t} \approx \frac{\Delta i_{L 2}}{\Delta t}=\frac{i_{L 2}[k]-i_{L 2}[k-1]}{T}$,

therefore, (1) is implemented as discrete implementation as:

$v_{c D C}[k]=v_{b a t}[k]-\frac{L_{2}}{T}\left(i_{b a t}{ }^{*}[k]-i_{b a t}[k]\right)$,

where $v_{b a t}$ denotes the voltage in the batteries, $i_{b a t}$ the charging current, $i_{b a t} *$ the reference, $L_{2}$ the inductance, and $T$ the sampling period. The influence of the inductor resistance is neglected, since it presents a very small value. The determined value of $v_{C D C}$ is compared with a triangular carrier in order to obtain the PWM signal for the IGBT $S_{5}$, while the IGBT $S_{6}$ is maintained off. On the other hand, the voltage that this converter must produce in order to maintain a charging process with constant voltage (CV) is obtained from: 
$v_{c D C}[k]=v_{b a t}{ }^{*}[k]-\frac{L_{2}}{T}\left(i_{\text {bat }}[k]-i_{\text {bat }}[k-1]\right)$,

where $v_{b a t} *$ is the voltage reference to charge the batteries. Also in this stage, the determined value is compared with a carrier to obtain a PWM signal. For both constant current and constant voltage stages, the references $\left(i_{b a t} *\right.$ and $\left.v_{b a t} *\right)$ are established by the battery management system (BMS). On the other hand, also during G2V mode, the ac-dc controls the EV current in the ac side. When the EV is plugged-in only in G2V mode, the EV current reference $\left(i_{e v}{ }^{*}\right)$ is sinusoidal. Analyzing the EV from the power grid point of view, it should operate as a linear electrical appliance, i.e., the relation between the voltage and the current is established as:

$I_{E V}=\frac{1}{Z_{E V}} V_{G}$,

where $I_{E V}$ and $V_{G}$ are rms values of current and voltage in the ac side. Therefore, the same reasoning can be established in terms of instantaneous values as:

$i_{e v}(t)=\frac{1}{Z_{E V}} v_{g}(t)$.

Neglecting the power losses, the active power in the ac side is composed by the power necessary to maintain the dc-link voltage regulated and the power necessary to charge the batteries, allowing to establish:

$P_{A C}=p_{d c}+p_{b a t}=\frac{V_{G}{ }^{2}}{Z_{E V}}$.

Using (5) in (4), the instantaneous ac current is determined by:

$i_{e v}(t)=\frac{p_{d c}+p_{b a t}}{V_{G}{ }^{2}} v_{g}(t)$.

As a contribution for high-levels of power quality in the power grid, the EV should operate with a sinusoidal current $\left(i_{e v}\right)$. Analyzing (6), it is identified that the current waveform is directly influenced by the power grid voltage waveform. Therefore, a power grid voltage with high harmonic content results in a current with the same harmonic content. This drawback can be avoided using the aforementioned PLL signal instead of the real power grid voltage. It is important to clarify that this power theory is used as base for establishing the current reference for all the operation modes. From (6), and since a digital control is implemented, the current is established according to:

$i_{e v}{ }^{*}[k]=\frac{p_{b a t}[k]+p_{d c}{ }^{*}[k]}{V_{G}[k]^{2}} v_{p l l s}[k]$,

where $V_{G}$ denotes the rms value of the grid voltage, $p_{b a t}$ the instantaneous value of the batteries power (i.e., $v_{b a t}$ multiplied by $i_{b a t}$, assuming a positive value during $\mathrm{G} 2 \mathrm{~V}$ mode and a negative value during V2G mode, due to the sensor position), and $p_{d c} *$ the instantaneous value of power necessary to control the dc-link voltage (obtained using a PI controller) according to its reference. The $p_{d c}$, is a small power that is necessary to exchange with the power grid to maintain the dc-link voltage controlled. In steady state operation, this power is positive and corresponds to the losses in the power converters. As aforementioned, the proposed $\mathrm{iV} 4 \mathrm{G}$ mode can occur simultaneously with the G2V mode. Therefore, maintaining the dc-dc control and changing the ac-dc control, the EV is able to compensate the current harmonics and the power factor of the electrical appliances plugged-in the same electrical installation. The proposed control equations for this operation mode are described as follows. When charging the batteries and producing reactive power, the EV current reference $\left(i_{e v}{ }^{*}\right)$ is obtained from:

$i_{e v}{ }^{*}[k]=\frac{\left(p_{\text {bat }}[k]+p_{d c}{ }^{*}[k]\right) v_{p l l s}[k]+Q^{*}[k] v_{\text {pllc }}[k]}{\left(V_{G}[k]\right)^{2}}$,

where $Q^{*}$ corresponds to the reactive power reference. On the other hand, besides charging the batteries and producing reactive power, when the EV is controlled to compensate current harmonics and power factor, the EV current reference $\left(i_{e v} *\right)$ is obtained from:

$i_{e v}{ }^{*}[k]=\frac{\left(p_{b a t}[k]+p_{d c}{ }^{*}[k]+\overline{p_{e a}}[k]\right) v_{\text {plls }}[k]}{\left(V_{G}[k]\right)^{2}}-i_{e a}[k]$,

where $\overline{p_{e a}}$ represents the average active power of the electrical appliances and $i_{e a}$ the instantaneous value of the electrical appliances current. This current is measured in the home electrical switchboard and can be transmitted to the EV charger by a wire or wireless interface. In this work, it is used a wired Hall effect current sensor with output in current, preventing voltage drops in case of log distances from the home electrical switchboard to the EV. The process for obtaining $p_{e a}$, and its average value, is described in detail in section III. C. The determined value of $\overline{p_{e a}}$ corresponds to the average active power of the electrical appliances that should be supplied by the power grid to the electrical appliances. With this value, and knowing the value of the power grid voltage, the ideal theoretical current is determined (at the fundamental frequency) in the power grid side. Therefore, the EV charger compensates the difference between the measured current in the electrical appliances and the calculated ideal current obtained from the average active power (i.e., it compensates the harmonics and the reactive power). A digital protection based on comparison was implemented in order to limit the ac current of the EV charger during the operation modes. After determining the EV current reference $\left(i_{e v} *\right)$, a predictive current control strategy is used to synthetize the voltage of the ac-dc converter. The control equation is obtained from the analysis established for the converter, where the current $i_{e v}[k+1]$ obtained from the time derivative of the inductor voltage is replaced by a reference value, allowing to establish a predictive control, i.e., the state of the converter is predicted for the next sampling interval. Analyzing the Fig. 3 in terms of the power grid voltage, the main equation for controlling the $\mathrm{EV}$ current is established as:

$v_{g}(\mathrm{t})-v_{C A C}(t)-v_{L 1}(t)=0$,

which can be rewritten as:

$\frac{d i_{L 1}(t)}{d t}-\frac{1}{L_{1}} v_{g}(t)+\frac{1}{L_{1}} v_{C A C}(t)=0$.

The discrete implementation of the control strategy, obtained considering the application of the backward Euler method as: 
$\frac{d i_{L 1}(t)}{d t} \approx \frac{\Delta i_{L 1}}{\Delta t}=\frac{i_{L 1}[k]-i_{L 1}[k-1]}{T}$,

and the predictive strategy presented in [36], results in:

$$
\begin{aligned}
v_{c A C}[k]=v_{g}[k]- & \frac{L_{1}}{T}\left(2 i_{e v}{ }^{*}[k]-i_{e v}{ }^{*}[k-1]-i_{e v}[k]\right. \\
& \left.-i_{\text {ev_error }}[k-1]\right),
\end{aligned}
$$

where $i_{e v}$ error denotes the current error. The IGBTs gate pulse patterns are obtained comparing the voltage reference $\left(v_{C A C}\right)$ with a triangular carrier $(20 \mathrm{kHz})$ through a unipolar PWM strategy.

\section{B. Discharging the EV Batteries}

From the moment that the EV is plugged-in, it can act to consume or supply energy. When the EV is used for providing energy to the power grid (V2G mode), the dc-dc converter is controlled in order to discharge the batteries with constant current, therefore, the voltage produced by the dc-dc converter $\left(v_{C D C}\right)$ is established by:

$v_{c D C}[k]=v_{b a t}+\frac{L_{2}}{T}\left(i_{b a t}{ }^{*}[k]-i_{b a t}[k]\right)$.

As for the G2V mode, the ac-dc converter controls the EV current in the ac side. When the EV is plugged-in only for the V2G mode, the EV current reference $\left(i_{e v}{ }^{*}\right)$ is also sinusoidal but in phase opposition relatively to the power grid voltage $\left(v_{g}\right)$. Therefore, the instantaneous value of the current reference is defined according to:

$i_{e v}{ }^{*}[k]=\frac{-p_{b a t}[k]+p_{d c}{ }^{*}[k]}{V_{G}[k]^{2}} v_{p l l s}[k]$.

The predictive current control strategy defined by (10) is also used to control the current reference defined in (12). As aforementioned, the proposed iV4G mode can also occur simultaneously with the V2G mode, representing an attractive contribution for the EV in smart grids. In this mode, the dc-dc control is maintained (since this operation mode does not require energy from the EV battery) and the ac-dc control is changed for providing reactive power and discharging the batteries, where, the reference current is defined according to:

$i_{e v}{ }^{*}[k]=\frac{\left(-p_{b a t}[k]+p_{d c}{ }^{*}[k]\right) v_{p l l s}[k]+Q^{*}[k] v_{p l l c}[k]}{\left(V_{G}[k]\right)^{2}}$.

During the $\mathrm{V} 2 \mathrm{G}$ mode, the proposed iV4G mode can also be associated to compensate the harmonic distortion and the power factor of the electrical installation. Therefore, the reference current for the ac-dc converter is defined according to:

$i_{e v}{ }^{*}[k]=\frac{\left(-p_{b a t}[k]+p_{d c}{ }^{*}[k]+\overline{p_{e a}}[k]\right) v_{p l l s}[k]}{\left(V_{G}[k]\right)^{2}}-i_{e a}[k]$.

\section{Improved Vehicle-for-Grid (iV4G) Operation Mode}

When the EV is plugged-in, but not performing the G2V or V2G modes, the charger can be used to compensate power quality problems (reactive power and current harmonics) in the electrical installation where it is plugged-in. In this mode, only the ac-dc converter is used, i.e., it is not exchanged any energy between the EV batteries and the power grid, representing an attractive advantage for the EV utilization as support for the grid power quality. When the EV charger is compensating current harmonics and power factor, it is necessary to measure the home current $\left(i_{h}\right)$ to establish the EV current reference $\left(i_{e v} *\right)$. Thereafter, the electrical appliances current $\left(i_{e a}\right)$ is determined subtracting the home current $\left(i_{h}\right)$ with the EV current $\left(i_{e v}\right)$. With the electrical appliances current $\left(i_{e a}\right)$ and the power grid voltage $\left(v_{g}\right)$ is determined the value of the instantaneous power and its average value by:

$\operatorname{sum}[k]=\operatorname{sum}[k-1]-p_{e a}[k-N]+p_{e a}[k]$,

$\overline{p_{e a}}[k]=\frac{\operatorname{sum}[k]}{N}$,

where $N$ corresponds to the number of samples acquired during each cycle of the grid voltage. Using a grid voltage frequency of $50 \mathrm{~Hz}, N$ corresponds to 800 samples with a sampling frequency of $40 \mathrm{kHz}$. Taking into account that a PLL algorithm is used, such value of samples can be easily adjusted according to the sampling frequency and the frequency of the power grid. Since the EV compensates the current harmonic distortion and the power factor, using the average value and the instantaneous value of the electrical appliances current, the instantaneous value of the EV current reference is determined according to:

$i_{e v}{ }^{*}[k]=\frac{\left(p_{d c}{ }^{*}[k]+\overline{p_{e a}}[k]\right) v_{p l l s}[k]}{V_{G}[k]^{2}}-i_{e a}[k]$.

When the EV is used only for producing reactive power, the EV charger must receive the reactive power reference. In a smart grid scenario, this reference is defined by an aggregator according to the benefits of the power grid manager. Using the reactive power reference, the EV current reference for the ac-dc converter is determined according to:

$i_{e v}{ }^{*}[k]=\frac{\left(p_{d c}{ }^{*}[k]\right) v_{p l l s}[k]+Q^{*}[k] v_{p l l c}[k]}{V_{G}[k]^{2}}$.

\section{EXPERIMENTAL VALIDATION}

The G2V, V2G, and the proposed iV4G operation mode, were validated in a laboratory environment with a bidirectional EV charger prototype connected to a single-phase electrical installation of $230 \mathrm{~V}, 16 \mathrm{~A}, 50 \mathrm{~Hz}$. The developed prototype is non-isolated, since, according to IEC 61851-1, the galvanic isolation should be assured only between the vehicle chassis and the traction batteries. It should be noted that the new operation mode (iV4G) can be implemented basically in terms of digital control algorithms, allowing to maintain the same hardware structure of a bidirectional EV charger (i.e., the EV charger will not be more expensive due to the proposed operation mode). The experimental results were obtained with a FLUKE 435 Analyzer and a digital oscilloscope Yokogawa DL708E. The experimental validation was performed with the developed EV charger plugged-in to the power grid, but due to the line impedances and the nonlinear electrical appliances connected in all the electrical installation of the university, the power grid voltage presents a significant harmonic distortion. Fig. 6(a) shows the electrical layout for obtaining the experimental results, and Fig. 6(b) shows the experimental setup used. A DSP TMS320F28335 was used to implement the proposed control algorithms. The developed prototype uses the IGBTs IXXR110N65B4H1, switched at $20 \mathrm{kHz}$, and the drivers SKHI61R. The nominal values of the input inductor $\left(L_{l}\right)$ 


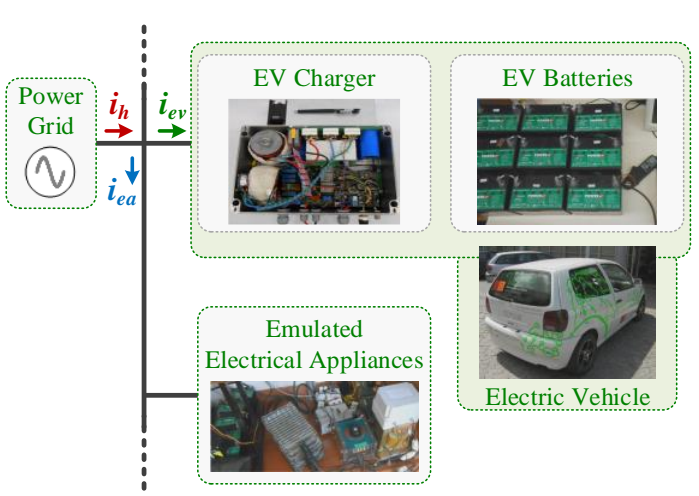

(a)

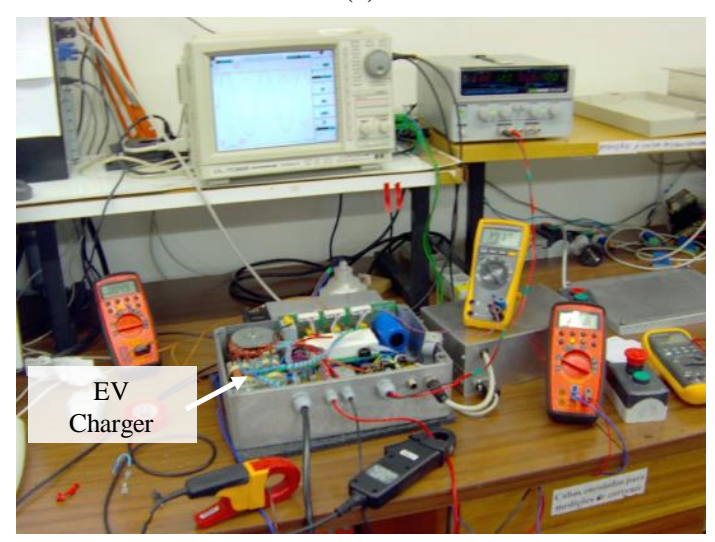

(b)

Fig. 6. Electrical layout (a) and experimental setup (b) used for obtaining the experimental results

and output inductor $\left(L_{2}\right)$, and rated currents, are respectively, $5 \mathrm{mH}, 20 \mathrm{~A}$ and $2 \mathrm{mH}, 12 \mathrm{~A}$. The nominal values of the dc-link capacitor $\left(C_{1}\right)$ and output capacitor $\left(C_{2}\right)$, and rated voltages, are respectively, $3 \mathrm{mF}, 450 \mathrm{~V}$ and $680 \mu \mathrm{F}, 400 \mathrm{~V}$. The switching ripple is negligible due to the value of the coupling inductors.

\section{A. Charging the EV Batteries}

This section is divided in two situations: (1) the EV is plugged-in only to charge the batteries (G2V mode); (2) the EV is plugged-in to perform the proposed $\mathrm{iV} 4 \mathrm{G}$ operation mode and to charge the batteries at the same time.

1) Case 1

This item shows the experimental results obtained during the $\mathrm{G} 2 \mathrm{~V}$ mode (i.e., the EV charger is only used to charge the batteries). Fig. 7 shows the power grid voltage $\left(v_{g}\right)$, the home current $\left(i_{h}\right)$, the electrical appliances current $\left(i_{e a}\right)$, and the EV current $\left(i_{e v}\right)$. The EV current is sinusoidal $(\mathrm{THD}=1.1 \%)$ with a high power factor $(\mathrm{TPF}=0.99)$ due to the control algorithm (cf. section III.A), the electrical appliances current is distorted (THD $=28.2 \%)$, and the home current is the sum of the previous, resulting in a THD of $9.3 \%$, which is harmful to the power grid in terms of power quality (e.g., contributes to the THD\% of the power grid voltage and to increase the neutral current in three-phase systems). In this case, the active power in the home is about $2.57 \mathrm{~kW}$.

2) Case 2

This item shows the experimental results obtained when the $\mathrm{EV}$ is plugged-in to perform the proposed $\mathrm{iV} 4 \mathrm{G}$ operation mode and to charge the batteries at the same time (G2V mode). Fig. 8

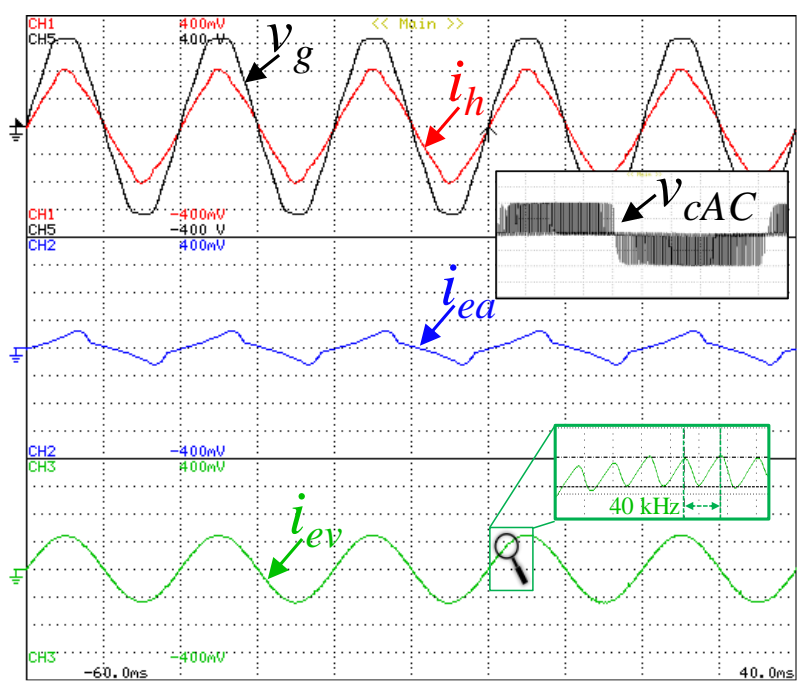

Fig. 7. Experimental results of the G2V mode: Power grid voltage $\left(v_{g}\right.$ : $100 \mathrm{~V} / \mathrm{div})$; Home current $\left(i_{h}: 10 \mathrm{~A} / \mathrm{div}\right)$; Electrical appliances current $\left(i_{e a}\right.$ : $10 \mathrm{~A} /$ div); EV current $\left(i_{e v}: 10 \mathrm{~A} /\right.$ div $)$

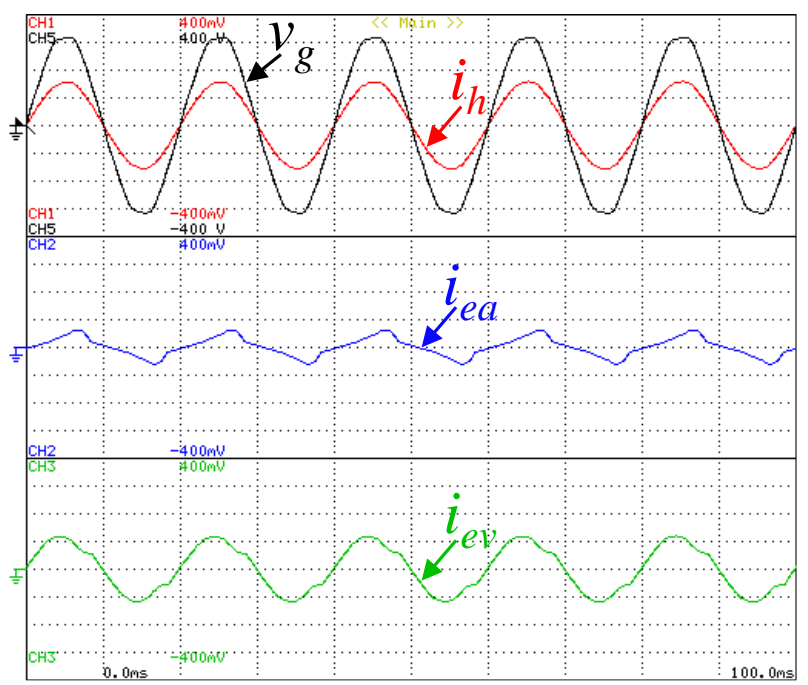

Fig. 8. Experimental results of the iV4G mode combined with the G2V operation mode: Power grid voltage $\left(v_{g}: 100 \mathrm{~V} / \mathrm{div}\right)$; Home current $\left(i_{h}\right.$ : $10 \mathrm{~A} /$ div); Electrical appliances current $\left(i_{e a}: 10 \mathrm{~A} / \mathrm{div}\right)$; EV current $\left(i_{e v}\right.$ : $10 \mathrm{~A} / \mathrm{div})$.

shows the power grid voltage $\left(v_{g}\right)$, the home current $\left(i_{h}\right)$, the electrical appliances current $\left(i_{e a}\right)$, and the EV current $\left(i_{e v}\right)$. In this case, the EV current has a harmonic distortion ( THD $=9.5 \%)$ due to the $\mathrm{iV4G}$ operation mode in order to obtain a sinusoidal home current $(\mathrm{THD}=1.7 \%)$. The active power in the home is $2.57 \mathrm{~kW}$ and the reactive power is practically zero, resulting in a TPF of 0.99 . This case represents one of the main contributions of this paper, i.e., an EV charger capable to compensate the harmonic distortion of the home current, which is caused by the nonlinear electrical appliances. Moreover, a sinusoidal home current contributes to reduce the harmonic distortion of the power grid voltage.

\section{B. Discharging the EV Batteries}

This section is also divided in two situations: (1) the EV is plugged-in and delivering energy from the batteries to the power grid (V2G mode); (2) the EV is plugged-in to perform the proposed $\mathrm{iV} 4 \mathrm{G}$ operation mode and to deliver energy to the 


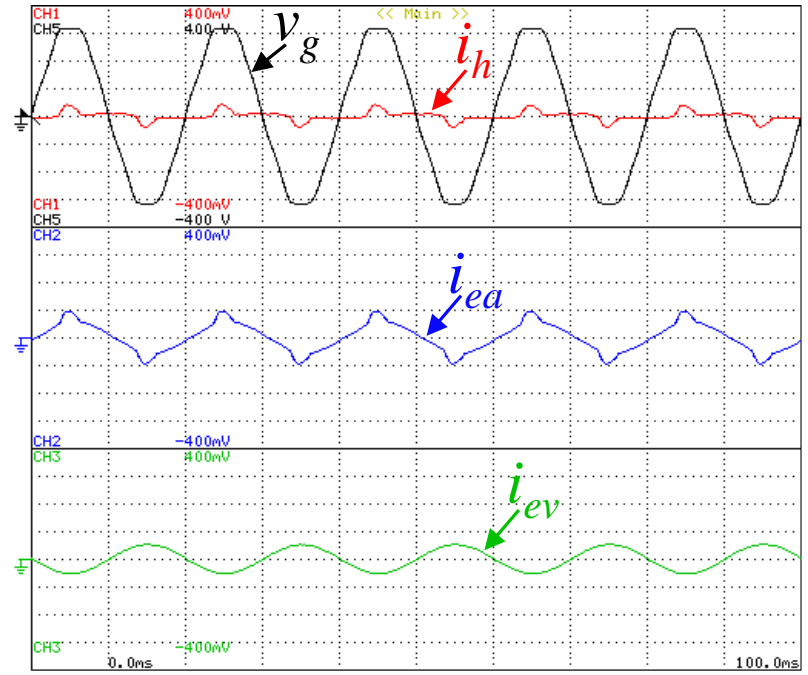

Fig. 9. Experimental results of the V2G mode: Power grid voltage $\left(v_{g}\right.$ : $100 \mathrm{~V} / \mathrm{div})$; Home current $\left(i_{h}: 10 \mathrm{~A} / \mathrm{div}\right)$; Electrical appliances current $\left(i_{e a}\right.$ : $10 \mathrm{~A} / \mathrm{div}) ; \mathrm{EV}$ current $\left(i_{e v}: 10 \mathrm{~A} / \mathrm{div}\right)$.

power grid.

\section{1) Case 1}

This item shows the experimental results of the V2G mode when is only delivered energy to the power grid. Fig. 9 shows the power grid voltage $\left(v_{g}\right)$, the home current $\left(i_{h}\right)$, the electrical appliances current $\left(i_{e a}\right)$, and the EV current $\left(i_{e v}\right)$. The EV current is sinusoidal (THD $=1.1 \%$ ) with a high power factor $(\mathrm{TPF}=0.99)$ due to the control algorithm (cf. section III.B). In this case, the THD of the total home current is $65.5 \%$, the active power is $0.28 \mathrm{~kW}$ and the TPF is 0.71 . As aforementioned, this is very harmful to the power grid in terms of power quality.

2) Case 2

This item shows the experimental results of the proposed iV4G mode combined with the batteries discharging process (V2G mode). Fig. 10 shows the power grid voltage $\left(v_{g}\right)$, the home current $\left(i_{h}\right)$, the electrical appliances current $\left(i_{e a}\right)$, and the EV current $\left(i_{e v}\right)$. The EV current is composed by the current to inject in the power grid plus the compensation current, resulting in a non-sinusoidal current (THD $=28.9 \%)$. Therefore, the THD of the home current is reduced to THD $=2.1 \%$, the active power is $0.29 \mathrm{~kW}$ and the TPF is increased to 0.99 . The EV current is almost equal to the electrical appliances current, meaning that only a reduced amount of electrical energy is consumed from the power grid, i.e., the electrical energy consumed in the home is provided by the EV. This operation mode is even more relevant considering that the EV can operate as energy backup system in case of fails of the power grid.

\section{C. iV4G Operation Mode}

The experimental results obtained during the proposed iV4G operation mode working alone are divided in the two cases: (1) the EV is plugged-in to compensate current harmonic distortion and reactive power; (2) the EV is plugged-in only to produce reactive power.

\section{1) Case 1}

This case shows the experimental results obtained with the EV charger operating only to compensate current harmonic distortion. Fig. 11 shows the power grid voltage $\left(v_{g}\right)$, the total

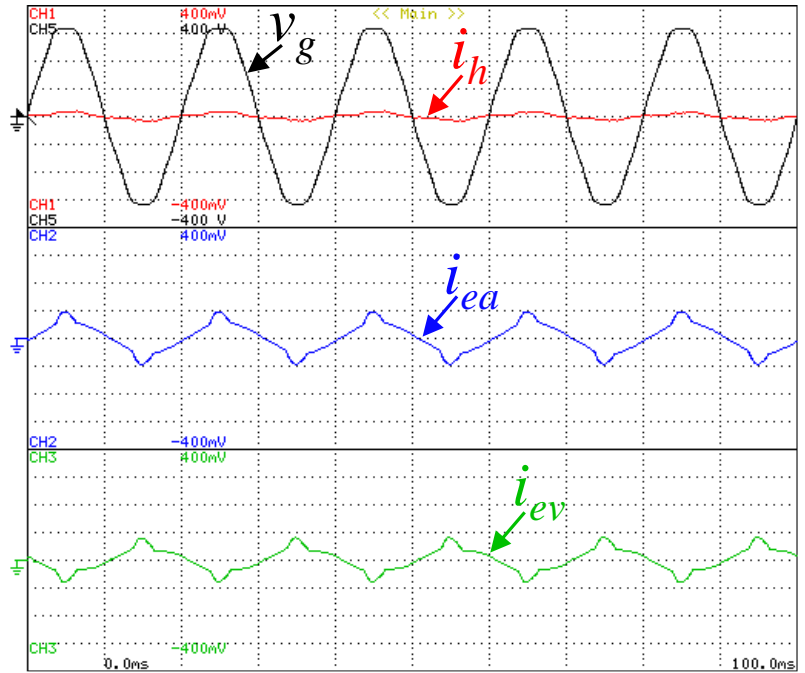

Fig. 10. Experimental results of the iV4G mode combined with the V2G operation mode: Power grid voltage $\left(v_{g}: 100 \mathrm{~V} / \mathrm{div}\right)$; Home current $\left(i_{h}\right.$ : $10 \mathrm{~A} /$ div $)$; Electrical appliances current $\left(i_{e a}: 10 \mathrm{~A} / \mathrm{div}\right)$; EV current $\left(i_{e v}\right.$ : $10 \mathrm{~A} / \mathrm{div})$.

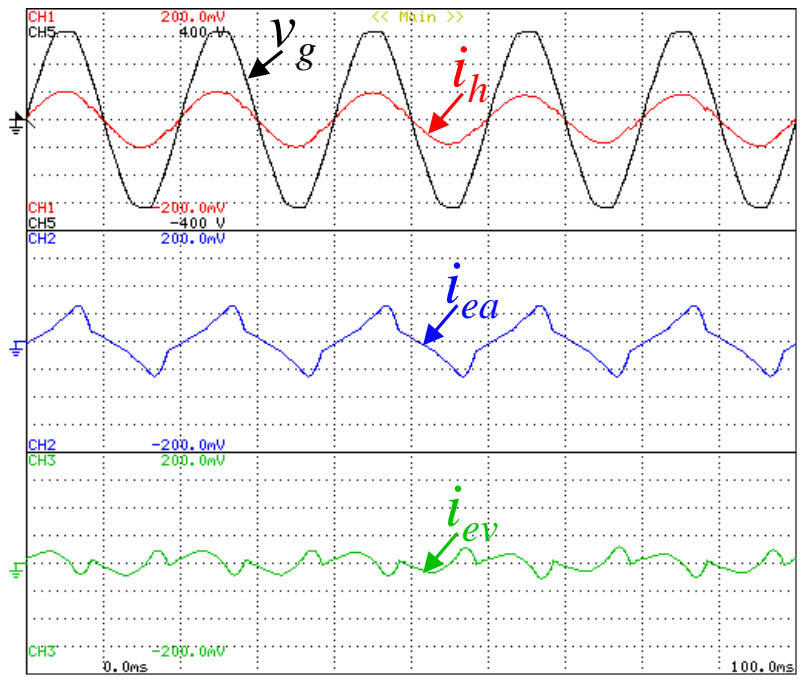

Fig. 11. Experimental results of the iV4G mode working alone compensating the current harmonic distortion and reactive power: Power grid voltage $\left(v_{g}: 100 \mathrm{~V} /\right.$ div $)$; Home current $\left(i_{h}: 5 \mathrm{~A} /\right.$ div$)$; Electrical appliances current $\left(i_{e a}: 5 \mathrm{~A} / \mathrm{div}\right) ; \mathrm{EV}$ current $\left(i_{e v}: 5 \mathrm{~A} / \mathrm{div}\right)$.

home current $\left(i_{h}\right)$, the electrical appliances current $\left(i_{e a}\right)$, and the EV current $\left(i_{e v}\right)$. The EV current is distorted (THD $=93.6 \%$ ), once it corresponds to the compensation current to make the total home current sinusoidal $(\mathrm{THD}=1.7 \%)$. In this case, the active power of the electrical appliances is $0.73 \mathrm{~kW}$ and the TPF is 0.99 . This case also represents one of the main contributions of this paper, i.e., the EV can be used to compensate current harmonic distortion in the electrical installation where it is plugged-in even when it is not charging the batteries.

\section{2) Case 2}

This case shows the experimental results obtained with the EV charger only producing reactive power. Fig. 12 shows the power grid voltage $\left(v_{g}\right)$, the total home current $\left(i_{h}\right)$, the electrical appliances current $\left(i_{e a}\right)$, and the EV current $\left(i_{e v}\right)$. It is important to note that this case is more specific for situations when the EV is plugged-in in any electrical installation, e.g., public charging stations. In such situations the EV charger receives the 


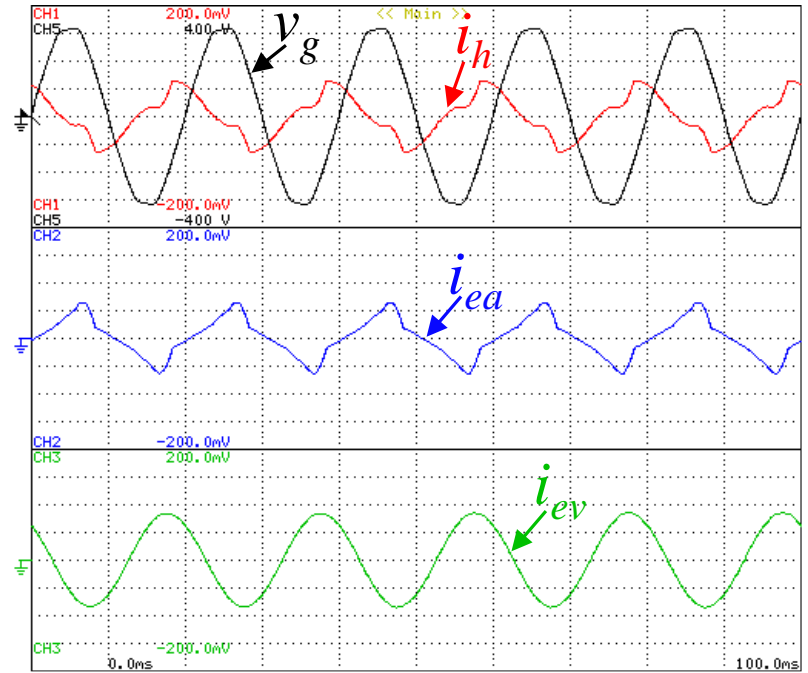

Fig. 12. Experimental results of the iV4G mode working alone only producing reactive power: Power grid voltage $\left(v_{g}: 100 \mathrm{~V} / \mathrm{div}\right)$; Home current $\left(i_{h}: 5 \mathrm{~A} / \mathrm{div}\right)$; Electrical appliances current $\left(i_{e a}: 5 \mathrm{~A} / \mathrm{div}\right)$; EV current $\left(i_{e v}: 5 \mathrm{~A} / \mathrm{div}\right)$.

TABLE II

HOME CURRENT $\left(i_{h}\right)$ Without AND WITH THE iV4G OPERATION MODE

\begin{tabular}{c|c|c|c}
\hline \multicolumn{2}{l|}{} & Without iV4G & With iV4G \\
\hline \hline EV Plugged-in & THD & $9.3 \%$ & $1.7 \%$ \\
and Charging & TPF & 0.98 & 0.99 \\
\hline EV Plugged-in & THD & $65.5 \%$ & $2.1 \%$ \\
and Discharging & TPF & 0.71 & 0.99 \\
\hline EV Plugged-in without & THD & $28.2 \%$ & $1.7 \%$ \\
Charging or Discharging & TPF & 0.96 & 0.99 \\
\hline \hline
\end{tabular}

reference of reactive power that it must produce according to the power grid benefits of the electrical installation where it is pugged-in. The EV current is sinusoidal (THD $=1.2 \%)$, but with a capacitive TPF of 0.45 . The active power (i.e., the active power of the electrical appliances) and reactive power are, respectively, $0.73 \mathrm{~kW}$ and $1.03 \mathrm{kVAr}$ (capacitive).

\section{Discussion}

Concerning the benefits of the iV4G proposed operation mode for smart grids in terms of power quality, Table II shows the THD and the TPF of the home current $\left(i_{h}\right)$ without and with the iV4G operation mode. For all the cases, with the EV charger operating with the proposed iV4G, the THD of the home current $\left(i_{h}\right)$ is reduced to a minimum value of $2.1 \%$ and the TPF increases to a maximum value of 0.99 . For such purpose, it is not required to use any of the stored energy in the EV batteries, representing the main advantage of the proposed mode (iV4G) for smart grids. Fig. 13 shows the spectral analysis and THD of the power grid voltage and current. Fig. 14 shows the EV battery current $\left(i_{b a t}\right)$ and the dc-link voltage $\left(v_{d c}\right)$ during the charging $(\mathrm{G} 2 \mathrm{~V})$ and discharging $(\mathrm{V} 2 \mathrm{G})$ modes. In both operation modes, the current increases with a ramp reference until the steady state operation value, avoiding sudden variations. During V2G mode the dc-link voltage must be greater than in G2V mode for the correct operation of the ac-dc converter. Fig. 15 shows different scenarios of operation for the proposed EV charger, illustrating in detail the dc-link voltage.

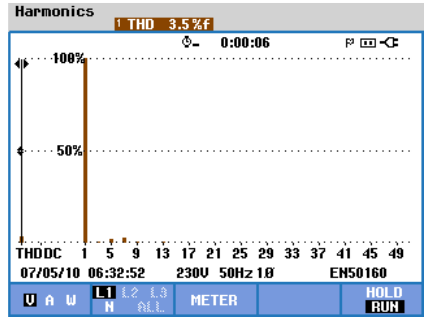

(a) (b)

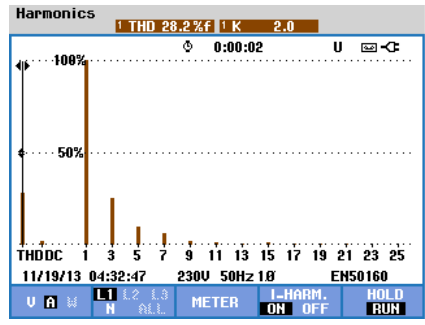

Fig. 13. Spectral analysis and THD: (a) Grid voltage and (b) current.

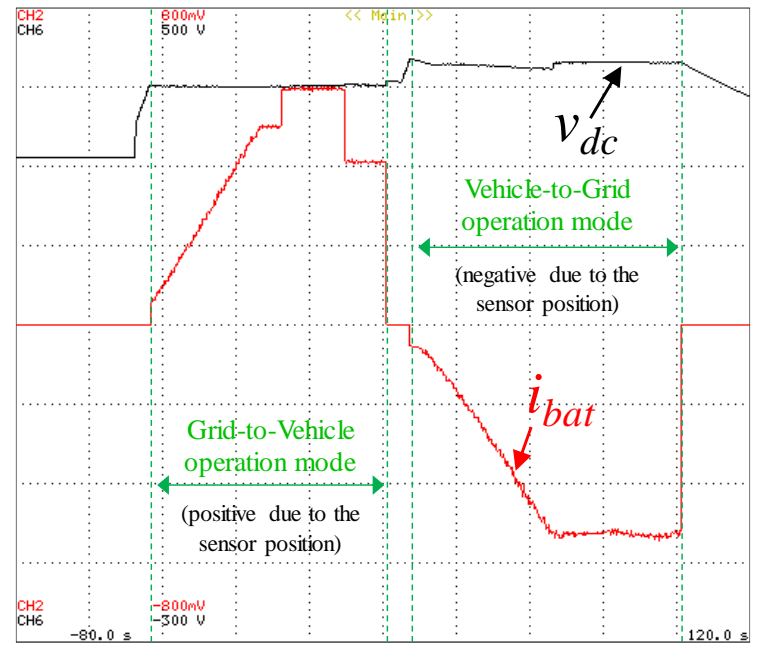

Fig. 14. Experimental results during G2V and V2G modes: EV battery current $\left(i_{b a t}: 2 \mathrm{~A} / \mathrm{div}\right)$; Dc-link voltage $\left(v_{d c}: 100 \mathrm{~V} / \mathrm{div}\right)$.
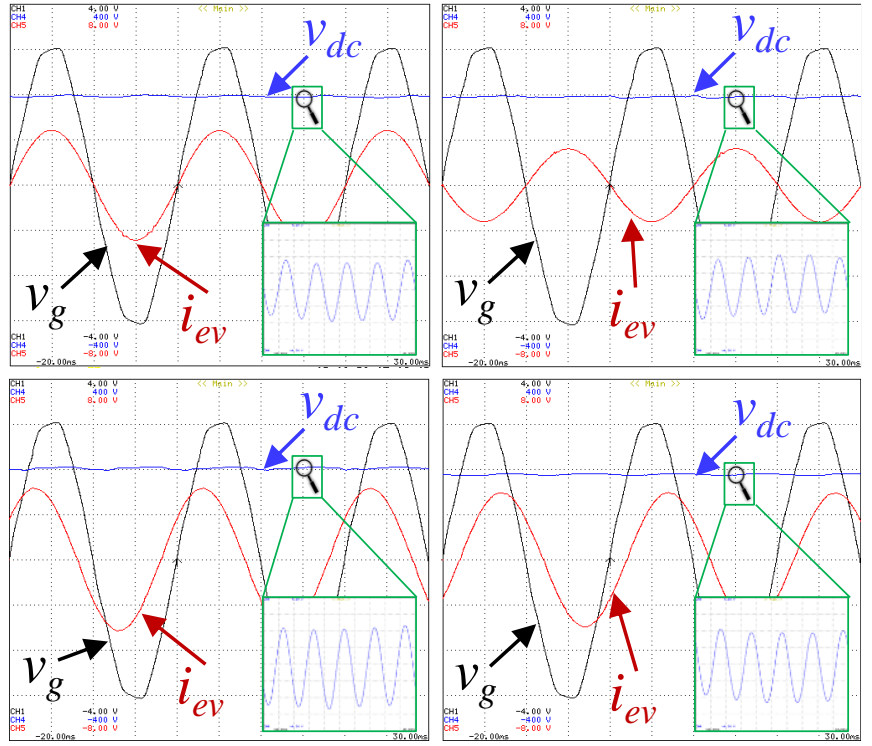

Fig. 15. Experimental results for different scenarios of operation of the EV charger, also illustrating a detail of the dc-link voltage: Power grid voltage $\left(v_{g}\right.$ : $100 \mathrm{~V} /$ div); EV current $\left(i_{e v}: 5 \mathrm{~A} /\right.$ div); Dc-link voltage ( $v_{d c}: 100 \mathrm{~V} /$ div).

\section{CONCLUSIONS}

A novel operation mode for EVs battery chargers is presented, which allows the compensation of current harmonics and power factor, improving the power quality of the smart grids. This proposed operation mode, denominated improved vehicle-for-grid (iV4G), contributes to demonstrate that EVs 
can represent an important asset for the future smart grids. However, it should be noted that to work in the iV4G operation mode the EV battery charger does not require any energy from the batteries to compensate current harmonics or the power factor (producing reactive power). Considering the distinct G2V, V2G and iV4G modes, the experimental results show the EV charger prototype working with the $\mathrm{iV} 4 \mathrm{G}$ operation mode alone, and also in combination with the G2V or V2G operation modes. The obtained experimental results confirm the correct operation and the advantages of the $\mathrm{iV} 4 \mathrm{G}$ operation mode in all cases, both in terms of compensation of current harmonics and reactive power, and also for producing reactive power according to the power grid requirement. Moreover, due to the current harmonics and reactive power compensation, the total power factor can be corrected to the unit, allowing reducing the rms value of the home current, contributing to mitigate power losses in the transport and distribution system.

\section{REFERENCES}

[1] Farzad Rajaei Salmasi, "Control Strategies for Hybrid Electric Vehicles: Evolution, Classification, Comparison, and Future Trends," IEEE Trans. Veh. Technol., vol.56, no.5, pp.2393-2404, Sept. 2007.

[2] João A. Peças Lopes, Filipe Soares, Pedro M. Rocha Almeida, "Integration of Electric Vehicles in the Electric Power Systems," Proc. IEEE, vol.99, no.1, pp.168-183, Jan. 2011.

[3] Kevin J. Dyke, Nigel Schofield, Mike Barnes, "The Impact of Transport Electrification on Electrical Networks," IEEE Trans. Ind. Electron., vol.57, no.12, pp.3917-3926, Dec. 2010.

[4] Sheldon S. Williamson, Akshay K. Rathore, Fariborz Musavi, "Industrial Electronics for Electric Transportation: Current State-of-theArt and Future Challenges," IEEE Trans. Ind. Electron., vol.62, no.5, pp.3021-3032, May 2015.

[5] Albert Y. S. Lam, Ka-Cheong Leung, Victor O. K. Li, "Capacity Estimation for Vehicle-to-Grid Frequency Regulation Services With Smart Charging Mechanism," IEEE Trans. Smart Grid, vol.7, no.1, pp.156-166, Jan. 2016.

[6] Adam Zipperer, Patricia A. Aloise-Young, Siddharth Suryanarayanan, Robin Roche, Lieko Earle, Dane Christensen, Pablo Bauleo, Daniel Zimmerle, "Electric Energy Management in the Smart Home: Perspectives on Enabling Technologies and Consumer Behavior," Proc. IEEE, vol.101, no.11, pp.2397-2408, Nov. 2013.

[7] Mingrui Zhang, Jie Chen, "The Energy Management and Optimized Operation of Electric Vehicles Based on Microgrid," IEEE Trans. Power Del., vol.29, no.3, pp.1427-1435, June 2014.

[8] Mosaddek Hossain Kamal Tushar, Chadi Assi, Martin Maier, Mohammad Faisal Uddin, "Smart Microgrids: Optimal Joint Scheduling for Electric Vehicles and Home Appliances," IEEE Trans. Smart Grid, vol.5, no.1, pp.239-250, Jan. 2014.

[9] Juan Van Roy, Niels Leemput, Frederik Geth, Jeroen Büscher, Robbe Salenbien, Johan Driesen, "Electric Vehicle Charging in an Office Building Microgrid with Distributed Energy Resources," IEEE Trans. Sustain. Energy, vol.5, no.4, pp.1389-1396, Oct. 2014.

[10] Ahmed Yousuf Saber, Ganesh Kumar Venayagamoorthy, "Plug-in Vehicles and Renewable Energy Sources for Cost and Emission Reductions,"IEEE Trans. Ind. Electron., vol.58, no.4, pp.1229-1238, Apr. 2011.

[11] Henrik Lund, Willett Kempton, "Integration of renewable energy into the transport and electricity sectors through V2G," Energy Policy, no.36, pp.3578-3587, July 2008.

[12] Shuang Gao, K. T. Chau, Chunhua Liu, Diyun Wu, C. C. Chan, "Integrated Energy Management of Plug-in Electric Vehicles in Power Grid With Renewables," IEEE Trans. Veh. Technol., vol.63, no.7, pp.3019-3027, Sept. 2014.
[13] Rong-Ceng Leou, "Optimal Charging/Discharging Control for Electric Vehicles Considering Power System Constraints and Operation Costs," IEEE Trans. Power Syst., vol.31, no.3, pp.1854-1860, May 2016.

[14] Murat Yilmaz, Philip T. Krein, "Review of the Impact of Vehicle-toGrid Technologies on Distribution Systems and Utility Interfaces," IEEE Trans. Power Electron., vol.28, no.12, pp.5673-5689, Dec. 2013.

[15] Vítor Monteiro, João Paulo Carmo, J. G. Pinto, João L. Afonso, “A Flexible Infrastructure for Dynamic Power Control of Electric Vehicle Battery Chargers," IEEE Trans. Veh. Technol., vol.65, no.6, pp.45354547, June 2016.

[16] Chunhua Liu, K. T. Chau, Diyun Wu, Shuang Gao, "Opportunities and Challenges of Vehicle-to-Home, Vehicle-to-Vehicle, and Vehicle-toGrid Technologies," Proc. IEEE, vol.101, no.11, pp.2409-2427, Nov. 2013.

[17] N. Z. Xu, C. Y. Chung, "Reliability Evaluation of Distribution Systems Including Vehicle-to-Home and Vehicle-to-Grid," IEEE Trans. Power Syst., vol.31, no.1, pp.759-768, Jan. 2016.

[18] Vítor Monteiro, J. G. Pinto, Bruno Exposto, João C. Ferreira, João L. Afonso, "Smart Charging Management for Electric Vehicle Battery Chargers," IEEE VPPC Vehicle Power and Propulsion Conference, pp.1-5, Oct. 2014.

[19] Leonardo Energy, "Poor Power Quality costs European business more than $€ 150$ billion a year," European Power Quality Survey, 2008.

[20] Roman Targosz, David Chapman, "The Cost of Poor Power Quality," European Copper Institute, Leonardo Energy, Application Note, Oct 2015.

[21] Qing Zhong, Wei Huang, Shun Tao, Xiangning Xiao, "Survey on Assessment of Power Quality Cost in Shanghai China," IEEE PES General Meeting Conference \&amp; Exposition, pp.1-5, July 2014.

[22] Márcio C. B. P. Rodrigues, Henrique J. Schettino, André A. Ferreira, Pedro G. Barbosa, Henrique A. C. Braga, "Active Power Filter Operation of an Electric Vehicle Applied to Single-Phase Networks," IEEE/IAS INDUSCON International Conference on Industry Applications, pp.1-8, Fortaleza Brazil, Nov. 2012.

[23] Márcio C. B. P. Rodrigues, Igor D. N. Souza, André A. Ferreira, Pedro G. Barbosa, Henrique A. C. Braga, "Simultaneous Active Power Filter and G2V (or V2G) Operation of EV On-Board Power Electronics," IEEE IECON Industrial Electronics Conference, pp.4684-4689, Vienna Austria, Nov. 2013.

[24] Mithat C. Kisacikoglu, Burak Ozpineci, Leon M. Tolbert, "Examination of a PHEV Bidirectional Charger System for V2G Reactive Power Compensation," IEEE APEC Applied Power Electronics Conference and Exposition, pp.458-465, Feb. 2010.

[25] Mithat C. Kisacikoglu, Metin Kesler, Leon M. Tolbert, "Single-Phase On-Board Bidirectional PEV Charger for V2G Reactive Power Operation," IEEE Trans. Smart Grid, vol.6, no.2, pp.767-775, Mar. 2015.

[26] Yao Sun, Weixia Liu, Mei Su, Xing Li, Hui Wang, Jian Yang, “A Unified Modeling and Control of a Multi-Functional Current SourceTyped Converter for V2G Application," ELSEVIER Electric Power Systems Research, vol.106, pp.12-20, Jan. 2014.

[27] Giuseppe Buja, Manuele Bertoluzzo, Christian Fontana, "Reactive Power Compensation Capabilities of V2G-Enabled Electric Vehicles," IEEE Trans. Power Electon., vol.32, no.12, pp.9447-9459, Dec. 2017.

[28] Vítor Monteiro, J. G. Pinto, Bruno Exposto, João C. Ferreira, Carlos Couto, João L. Afonso, "Assessment of a Battery Charger for Electric Vehicles with Reactive Power Control," IEEE IECON Industrial Electronics Conference, pp.5124-5129, Oct. 2012.

[29] Vítor Monteiro, J. G. Pinto, João L. Afonso, “Operation Modes for the Electric Vehicle in Smart Grids and Smart Homes: Present and Proposed Modes," IEEE Trans. Veh. Tech., vol.65, no.3, pp.1007-1020, Mar. 2016.

[30] A. R. Boynuegri, M. Uzunoglu, O. Erdinc, E. Gokalp, “A new perspective in grid connection of electric vehicles: Different operating modes for elimination of energy quality problems," ELSEVIER Applied Energy, vol.132, pp.435-451, Nov. 2014.

[31] Márcio C. B. P. Rodrigues, Igor Souza, André A. Ferreira, Pedro G. Barbosa, Henrique A. C. Braga, "Integrated bidirectional single-phase vehicle-to-grid interface with active power filter capability," COBEP Power Electronics Conference (COBEP), pp.993-1000, Oct. 2013. 
[32] Lutz Rauchfuß, Jérémie Foulquier, Ralf Werner, "Charging Station as an Active Filter for Harmonics Compensation of Smart Grid," IEEE ICHQP International Conference on Harmonics and Quality of Power, pp.181184, May 2014.

[33] Huachun Han, Chenyu Zhang, Zhenhua Lv, Di Huang, "Power Control Strategy of Electric Vehicle for Active Distribution Network," IEEE IECON Industrial Electronics Conference, pp.3907-3911, Nov. 2017.

[34] M. Karimi-Ghartemani, M. R. Iravani, "A Nonlinear Adaptive Filter for Online Signal Analysis in Power Systems: Applications," IEEE Trans. Power Del., vol.17, no.2, pp.617-622, Apr. 2002.
[35] Ala Al-Haj Hussein, Issa Batarseh, "A Review of Charging Algorithms for Nickel and Lithium Battery Chargers," IEEE Trans. Veh. Technol., vol.60, no.3, pp.830-838, Mar. 2011.

[36] Vítor Monteiro, J. G. Pinto, João L. Afonso, “Operation Modes for the Electric Vehicle in Smart Grids and Smart Homes: Present and Proposed Modes," IEEE Trans. Veh. Tech., vol.65, no.3, pp.1007-1020, Mar. 2016. 
